\title{
Photoresponsive Organic-Inorganic Hybrid Ferroelectric Designed at the Molecular Level
}

Wei-Jian Xu, ${ }^{\dagger}, \$$, Konstantin Romanyuk,,$^{+,}{ }^{\perp}$ José M. G. Martinho, ${ }^{\prime}$ Ying Zeng, ${ }^{\dagger}$ Xue-Wen Zhang, ${ }^{\dagger}$ Andrei

Ushakov, ${ }^{\perp}$ Vladimir Shur, ${ }^{\perp}$ Wei-Xiong Zhang, ${ }^{*, \dagger}$ Xiao-Ming Chen, ${ }^{\dagger}$ Andrei Kholkin,,$\stackrel{\star}{\star}$ and João Rocha ${ }^{*}$,

${ }^{\dagger}$ MOE Key Laboratory of Bioinorganic and Synthetic Chemistry, School of Chemistry, Sun Yat-Sen University, Guangzhou 510275, China.

* Department of Physics \& CICECO-Aveiro Institute of Materials, University of Aveiro, 3810-193 Aveiro, Portugal

${ }^{\S}$ Department of Chemistry \& CICECO-Aveiro Institute of Materials, University of Aveiro, 3810-193 Aveiro, Portugal

" CQE- Centro de Química Estrutural, Instituto Superior Técnico, Universidade de Lisboa, 1049-001 Lisboa, Portugal

${ }^{\perp}$ School of Natural Sciences and Mathematics, Ural Federal University, 620000 Ekaterinburg, Russia 


\section{Experimental Procedures}

Synthesis. All chemicals were commercially available and were used without further purification. Red rod-like crystals of 1 were obtained by slow evaporation of aqueous solutions containing dimethylamine hydrochloride (40 mmol) and $\mathrm{Na}_{2}\left[\mathrm{Fe}(\mathrm{CN})_{5}(\mathrm{NO})\right] \cdot 2 \mathrm{H}_{2} \mathrm{O}(10 \mathrm{mmol})$ at room temperature, in $82 \%$ yield, based on Fe. Elemental analysis, calcd (\%) for 1 $\left(\mathrm{C}_{7} \mathrm{H}_{8} \mathrm{FeN}_{7} \mathrm{NaO}\right): \mathrm{C}, 29.49 ; \mathrm{N}, 34.40 ; \mathrm{H}, 2.83$. Found, C, 29.52; N, 33.72; H, 2.649.

Elemental analysis. Elemental $(\mathrm{C}, \mathrm{H}$, and $\mathrm{N})$ analyses were performed on a Perkin-Elmer Vario EL elemental analyzer with assynthesized samples.

Thermal Analysis. Thermogravimetric analyses (TGA) were carried out on a TA Q50 system with a heating rate of $5 \mathrm{Kmin}^{-1}$ under a dinitrogen atmosphere. Differential scanning calorimetry (DSC) was carried out on a TA Q2000 instrument under a dinitrogen atmosphere in aluminum crucibles with heating and cooling rates of $5 \mathrm{~K} \mathrm{~min}^{-1}$ from $298 \mathrm{~K}$ to $413 \mathrm{~K}$.

Dielectric measurements. The dielectric measurements were performed on a TH2828A impedance analyzer at selected frequencies from 27050 to $1073439 \mathrm{~Hz}$, with an amplitude of $1.0 \mathrm{~V}$, and a temperature sweeping rate of ca. $5 \mathrm{~K} / \mathrm{min}$ in a Mercury iTC cryogenic environment controller of Oxford Instrument. Au wire attached by silver conduction paste deposited on the single crystal surfaces was used as the electrodes.

PFM measurements. Imaging of the topography, domain configurations with high spatial resolution and ferroelectric switching were carried out by scanning probe microscopy (SPM) technique using piezoresponse force microscopy (PFM) mode implemented in the NTEGRA Aura scanning probe microscope (NT-MDT, Russia) equipped with the HF2LI lock-in amplifier (Zurich Instruments, Switzerland) and SPM probes for PFM measurements (High Resolution Silicon cantilevers of NSG01/Pt series with PtIr conductive coating with a resonance frequency of $\sim 150 \mathrm{kHz}$ and a force constant of $\sim 5 \mathrm{~N} / \mathrm{m}$ ). The PFM measurements were done with an ac voltage frequency of $21 \mathrm{kHz}$ and an amplitude of $10 \mathrm{~V}$ (PFM loops) and $20 \mathrm{~V}$ (PFM imaging).

Piezoelectric measurements. Inverse piezoelectric effect: for the measurements of the small electric field induced displacements of poled single crystal under the $20 \mathrm{kV} / \mathrm{cm}$, we used a standard scheme of single-beam Michelson homodyne interferometer (Figure S5). Direct piezoelectric effect: direct piezoelectric coefficient $d_{33}$ were measured with a quasi-static $d_{33}$ piezoelectric instrument (YE 2730A). The single crystal was carefully mounted between the two electrodes of the piezoelectric instrument (Figure S7).

P-E hysteresis loops measurements. $P$ - $E$ hysteresis measurements of 1 were done on a ca. $1.5 \times 1.5 \times 1.8 \mathrm{~mm}^{3}$ sized single crystal sample with silver paste electrodes in silicon oil. Bipolar triangular pulse of $10 \mathrm{~Hz}$ frequency pulses were generated by data acquisition (DAQ) board NI PCI-6251 (National Instruments Corp., USA) and amplified using a high voltage amplifier TREK 10/10B-HS (Trek Inc., USA). The switching current was measured using the op-amp-based feedback ammeter synchronously with applied voltage. The amplitudes of the applied electric field were $8,20,40$, and $60 \mathrm{kV} / \mathrm{cm}$. The $P$-E loops were obtained without any correction.

UV-Vis spectroscopy. Ultraviolet-vis (UV-Vis) diffuse absorption spectra were carried out on a Shimadzu UV-3600 spectrometer with measurement range from 200 to $800 \mathrm{~nm}$.

Infrared (IR) spectroscopy. The transmission infrared spectra of the complex were scanned at $77 \mathrm{~K}$, mounting the $\mathrm{KBr}$ pellet of the fine powder of 1 at $45^{\circ}$ in a liquid nitrogen cooled cryostat, in order to allow laser irradiation between spectra without changing the geometry. The cut-off of the cryostat windows is $1000 \mathrm{~cm}^{-1}$. A Bruker V70 FTIR spectrometer, equipped with a MCT wide band detector, was used, with $4 \mathrm{~cm}^{-1}$ resolution. To detect the formation of photoinduced isomers, Infrared spectra were scanned immediately after irradiating with a mode-locked Vanguard Green Laser $(2 \mathrm{~W}$ at $532 \mathrm{~nm})$ from Spectra Physics, at a pulse repetition rate of $76 \mathrm{MHz}$ with $\sim 10 \mathrm{ps}$ pulse width. The laser beam diameter $\left(1 / \mathrm{e}^{2}\right)$ was $1.4 \mathrm{~mm}$ at which corresponds a maximum power density of $250 \mathrm{~W} \mathrm{~cm}^{-2}$ for a Gaussian pulse. The density power of the laser was reduced using neutral density filters to $80 \mathrm{~W} \mathrm{~cm}^{-2}$, and the sample was irradiated for 5, 20, 50, 80 and $100 \mathrm{~min}$ (total times), at $77 \mathrm{~K}$. The power density of the laser is very high but due to geometrical constrains not all the output laser light reached the sample. The conversion of the ground sate to the metastable states 
SI and SII is very low as estimated by the very small decrease of the area of the $v(\mathrm{NO})$ band of the ground state. It was confirmed that after returning to room temperature the IR spectra of the ground state was recovered indicating that no photodegradation occurs during irradiation.

\section{X-ray crystallographic analyses}

The in-situ variable-temperature single-crystal diffraction intensities were collected on a Rigaku XtaLAB P300DS single-crystal diffractometer with graphite monochromated $\mathrm{Cu}-\mathrm{Ka}$ radiation $(\lambda=1.54184 \AA)$. The CrystalClear software package (Rigaku) was used for data collection, cell refinement, and data reduction. Absorption corrections were applied by using multi-scan program REQAB ${ }^{[1]}$ The structures were solved by direct methods and refined using full-matrix least-squares methods with the SHELX program package ${ }^{[2]}$ and Olex ${ }^{2}$ program. ${ }^{[3]}$ The atomic displacement parameters for non-hydrogen atoms were refined anisotropically, and the positions of the hydrogen atoms were generated geometrically. HKL 5 refinement was applied for the twinning structure of the LT phase. The crystal data and structure refinement results for $\mathbf{1}$ are listed in Table S1. Selected bond distances and bond angles are listed in Table S2.

Polycrystalline sample for powder X-ray diffraction (PXRD) measurements was prepared by fast evaporation of aqueous solutions containing dimethylamine hydrochloride and $\mathrm{Na}_{2}\left[\mathrm{Fe}(\mathrm{CN})_{5}(\mathrm{NO})\right] \cdot 2 \mathrm{H}_{2} \mathrm{O}$ at $333 \mathrm{~K}$. The variable-temperature PXRD data was collected on Panalytical Empyrean with Cu-Ka X-ray radiation (40 kV, $45 \mathrm{~mA})$ and TTK chamber from Anton Paar. The stepscanned PXRD data was recorded in the $2 \theta$ range of $6-50^{\circ}$ with $2 \theta$ step of $0.02^{\circ}$ and scan speed of 0.4 seconds/step. Pawley refinement of the experimental PXRD patterns were performed using the Reflex module of Material Studio $5 .{ }^{[4]}$ 


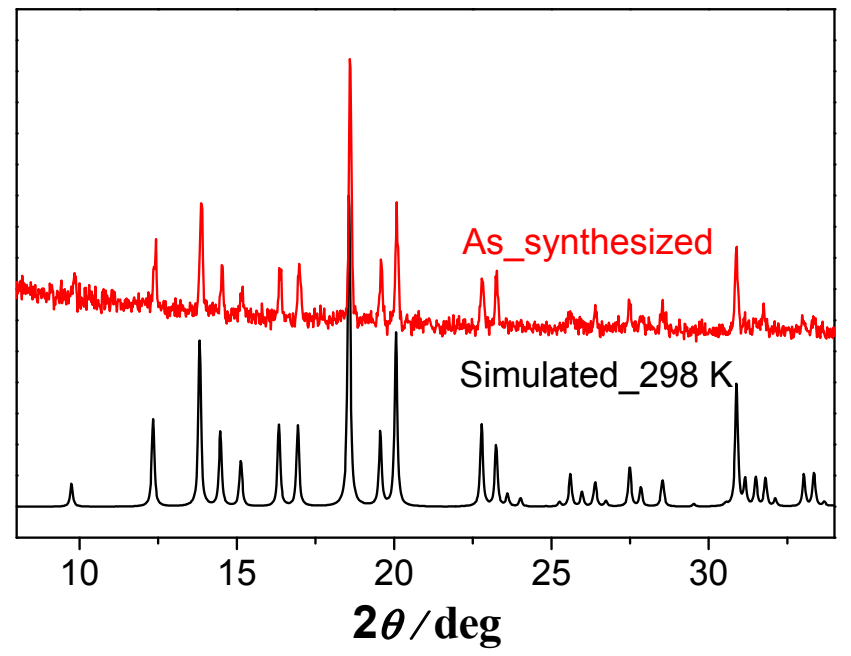

Figure S1. Powder X-ray diffraction confirms the phase purity of the as-synthesized sample at room temperature.

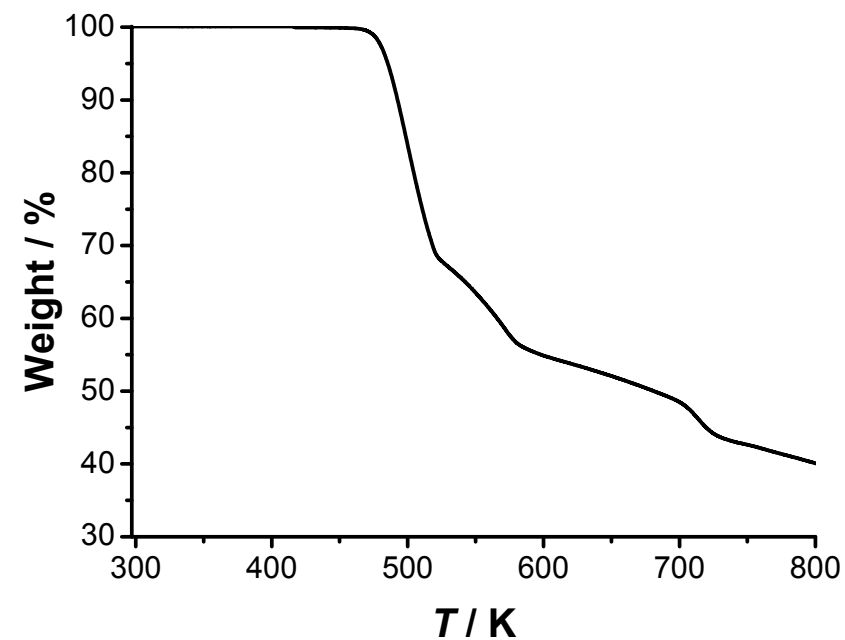

Figure S2. Thermogravimetry trace of $\mathbf{1}$.

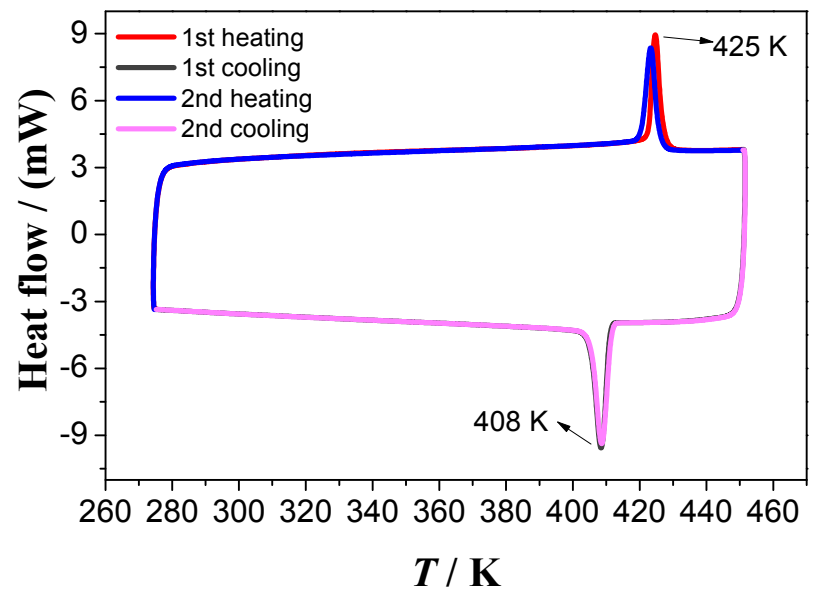

Figure S3. DSC curves of 1 measured in two heating-cooling cycles. 


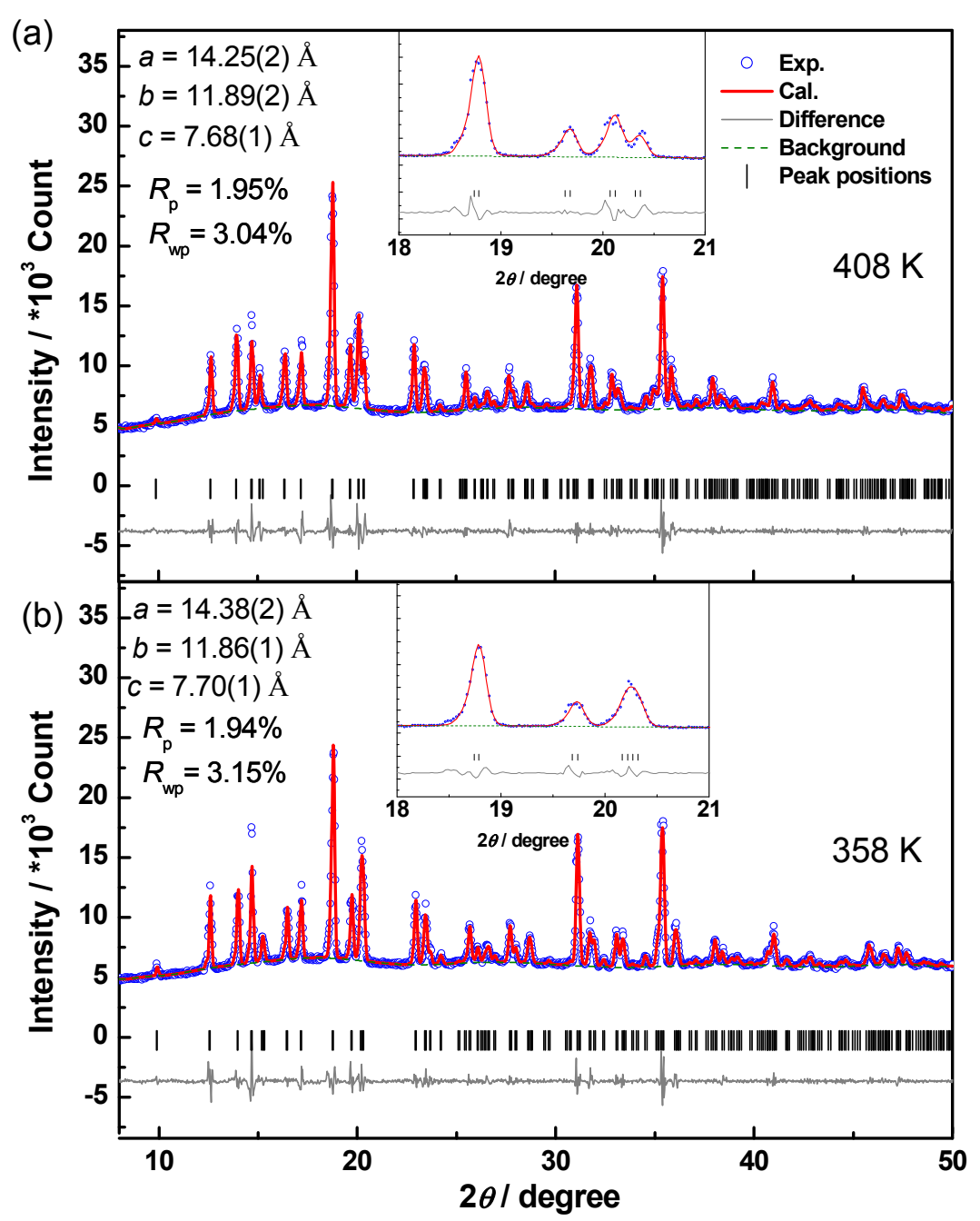

Figure S4. PXRD Pawley refinement of as-synthesized 1 at $408 \mathrm{~K}$ (a) and $358 \mathrm{~K}$ (b), space group Pna2 ${ }_{1}$. Experimental pattern (blue circles), calculated pattern (red line), difference profile (grey line) and background profile (dashed line). Stick marks (|) at the bottom of the pattern indicate peak positions allowed by the unit-cell parameters and space group. 


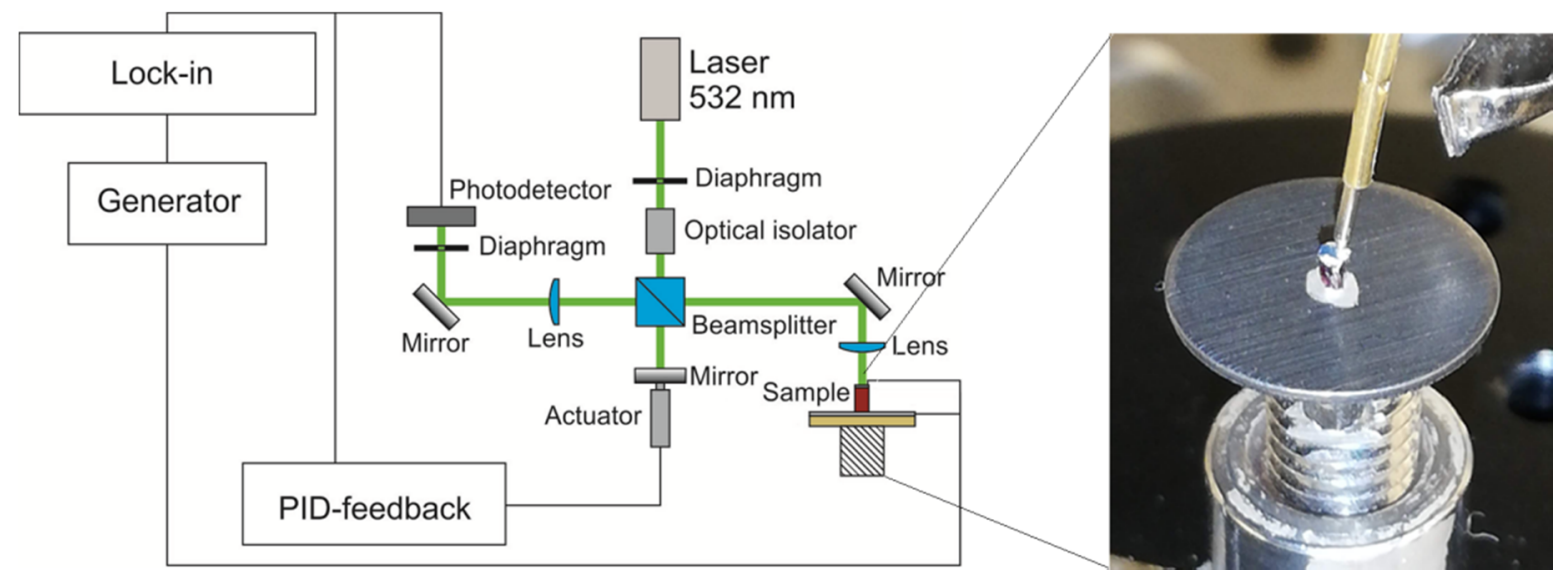

Figure S5. Scheme of piezoelectric measurement on single crystal of 1 on a Michelson-Morley interferometer.

(a)

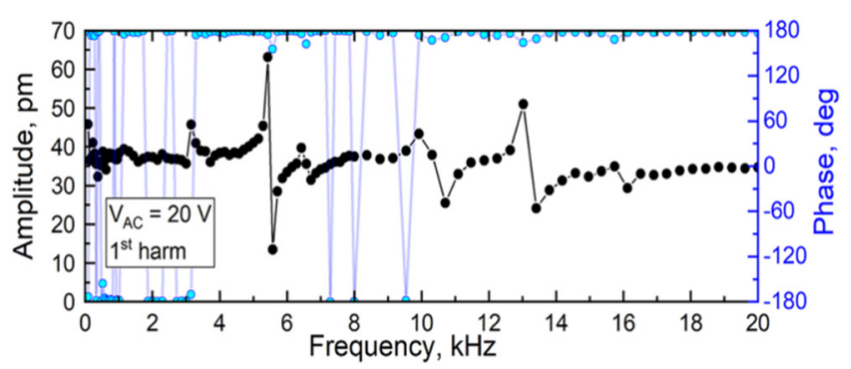

(b)

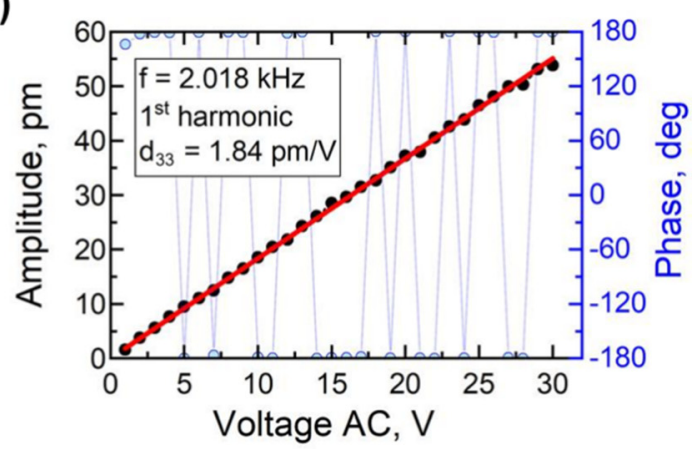

Figure S6. (a) Frequency and (b) AC voltage dependencies of the piezoelectric response of $\mathbf{1}$ measured on the interferometer.

(a)

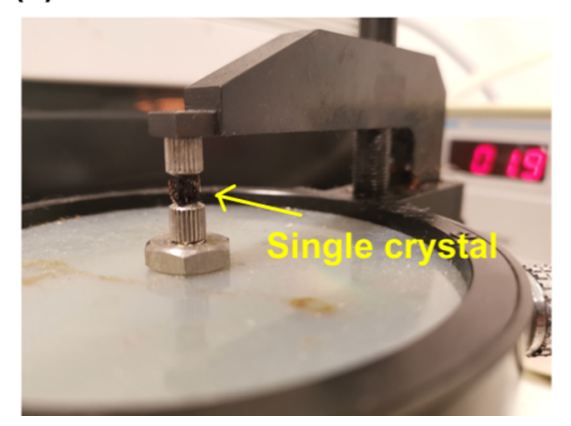

(b)

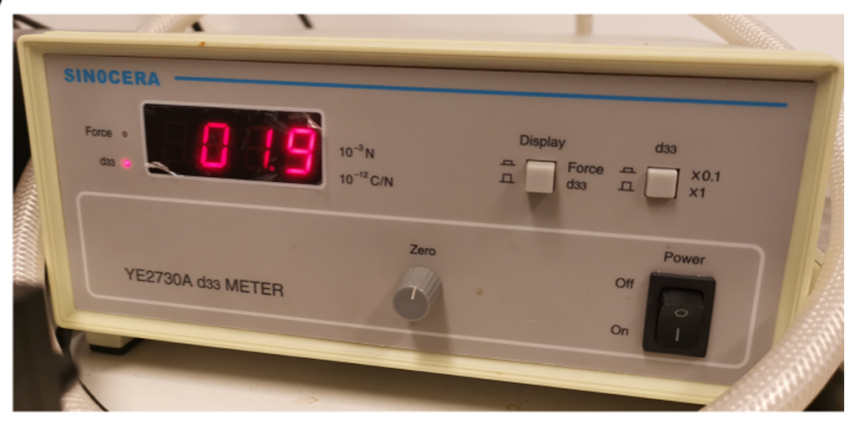

Figure S7. Direct piezoelectric effect of 1. (a) A picture of the single crystal of $\mathbf{1}$. (b) Recording the piezoelectric coefficient $d_{33}$ of $\mathbf{1}$ along the $c$-axis. 


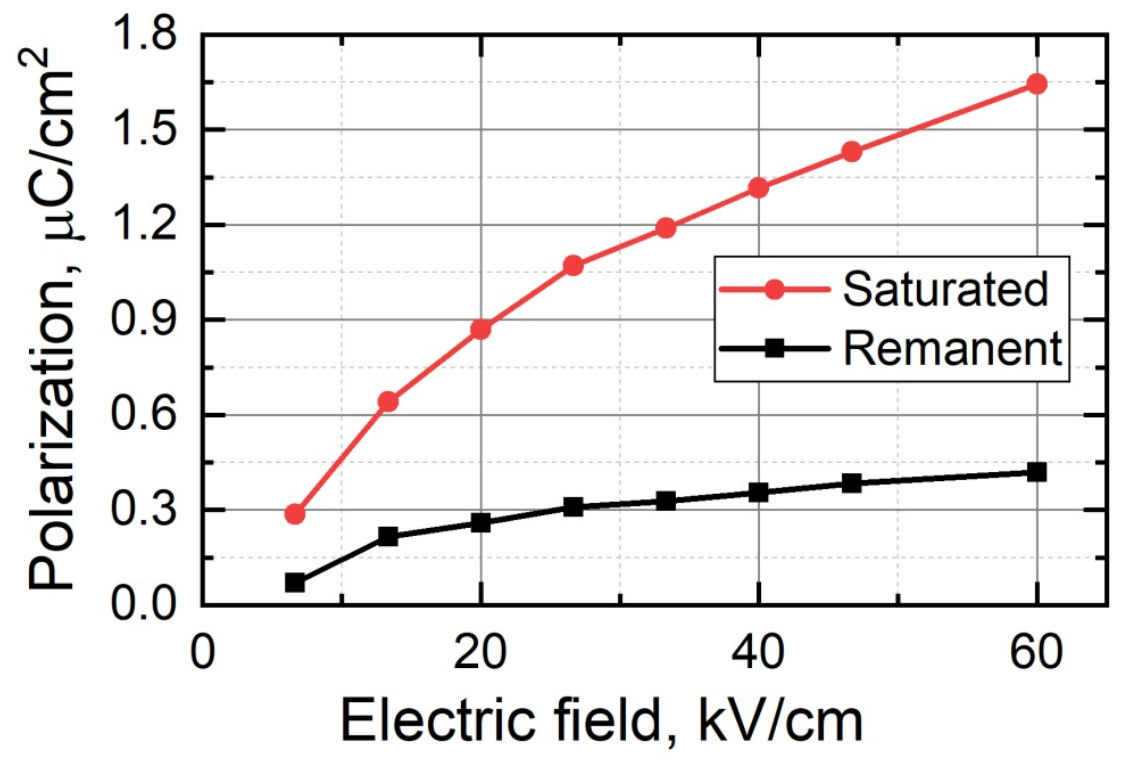

Figure S8. Electric field dependence of saturated and remanent polarization of $\mathbf{1}$.

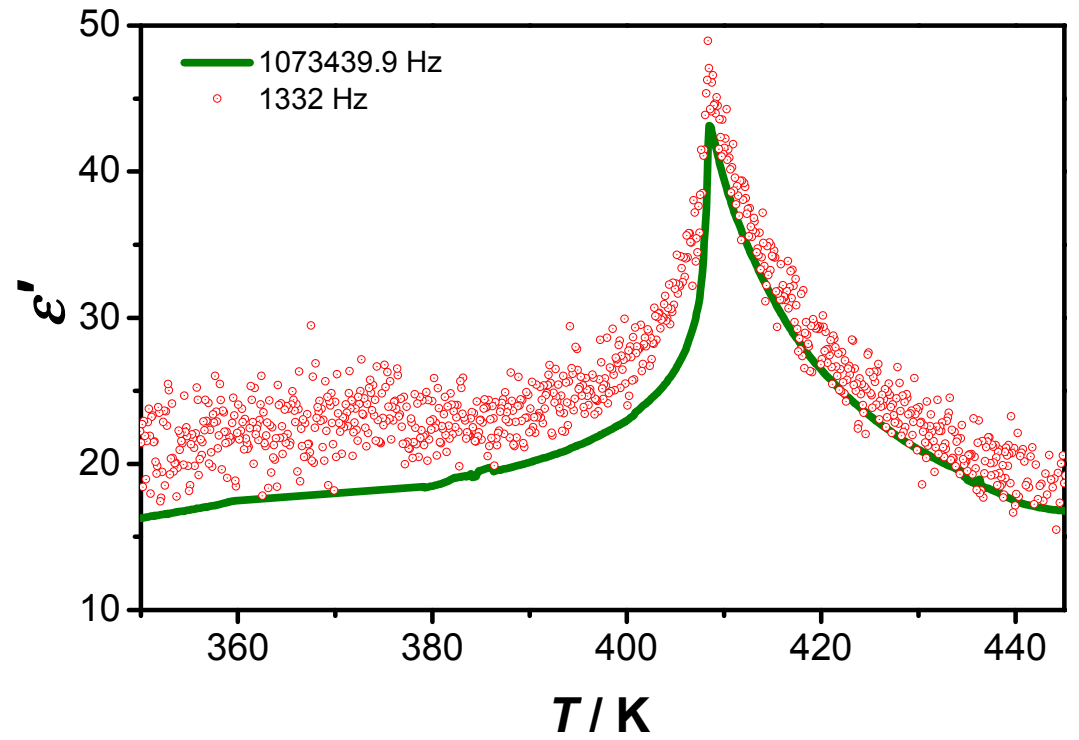

Figure S9. Temperature dependence of the dielectric constant of 1 along the $c$-axis measured at selected high and low frequencies at $1073439.9 \mathrm{~Hz}$ and $1332 \mathrm{~Hz}$ in a cooling mode. 


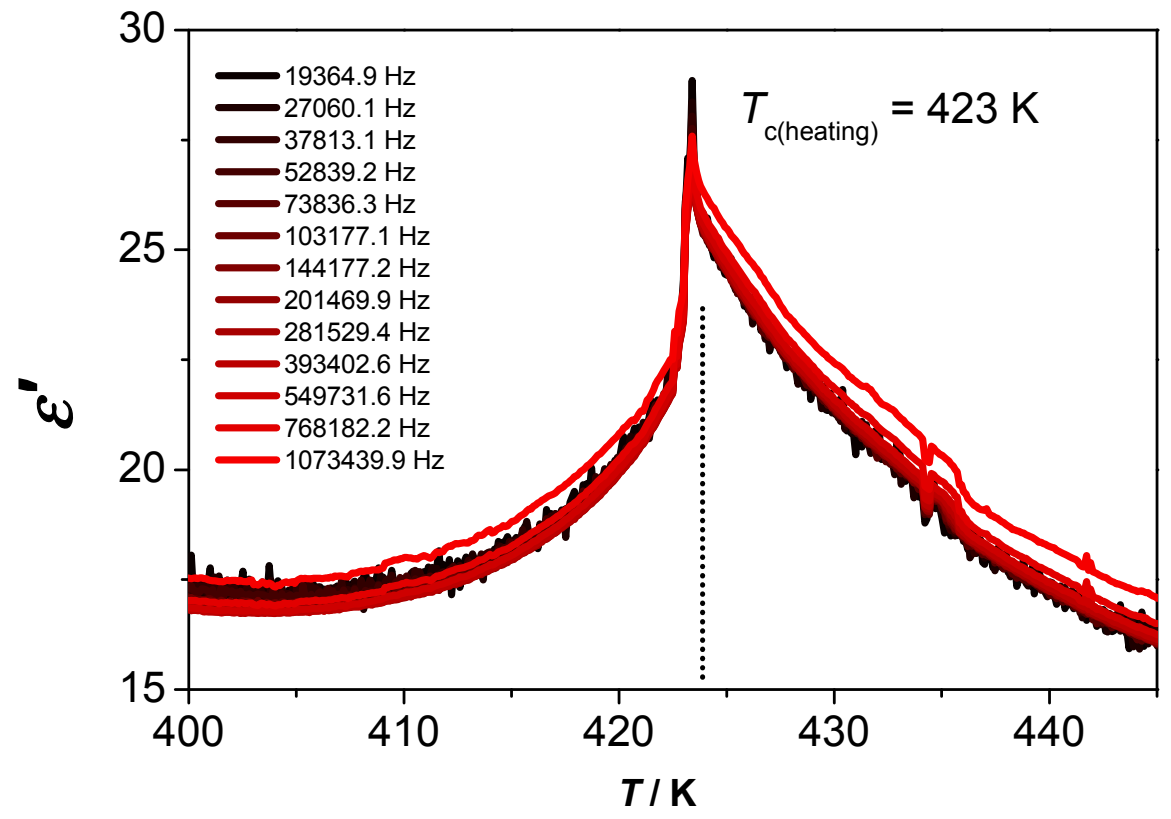

Figure S10. Temperature dependence of the dielectric constant of $\mathbf{1}$ along the $c$-axis at various frequencies in a heating mode.

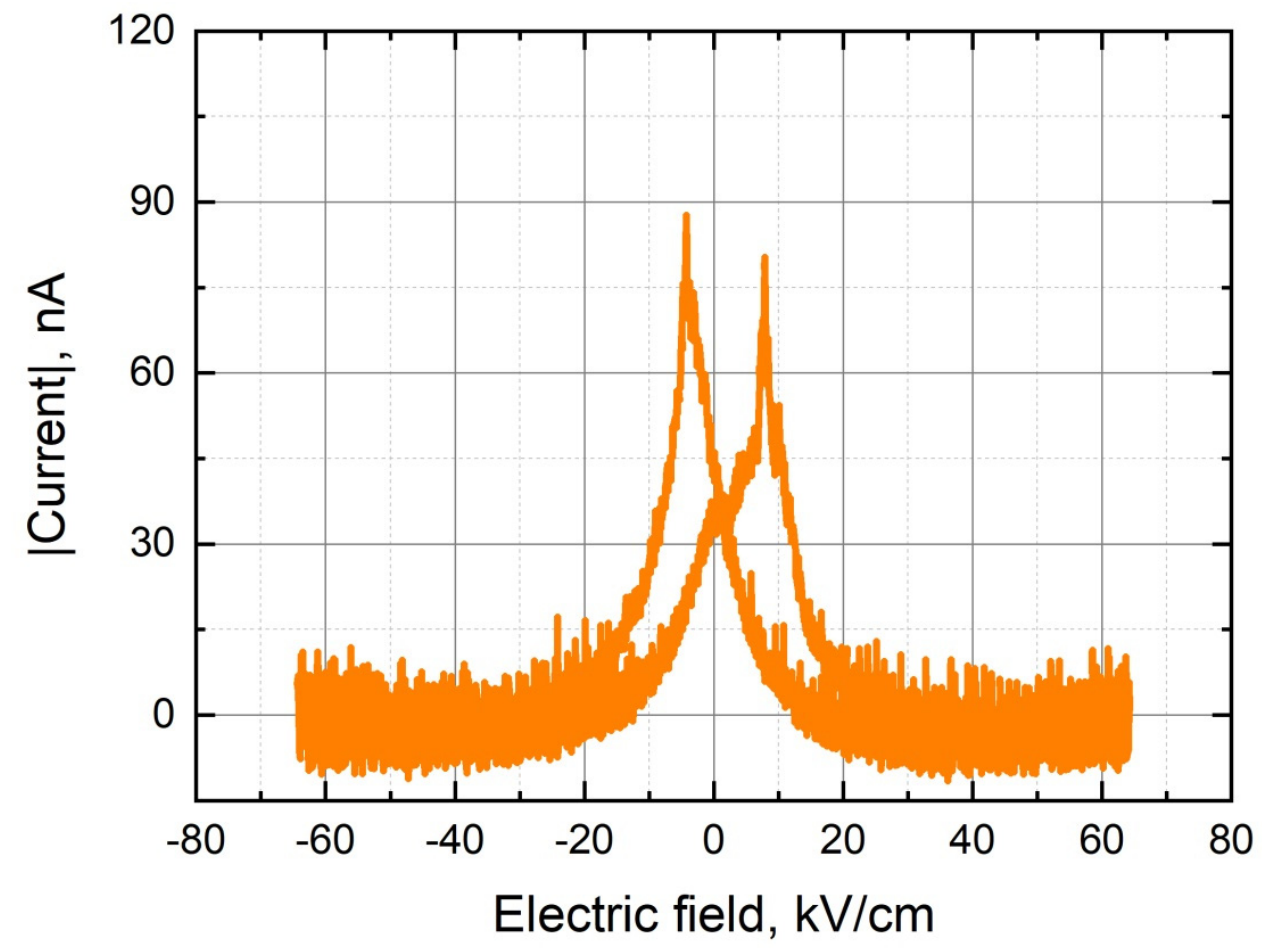

Figure S1 1. The derivative of the room temperature hysteresis loop measured at $65 \mathrm{kV} / \mathrm{cm}$. 


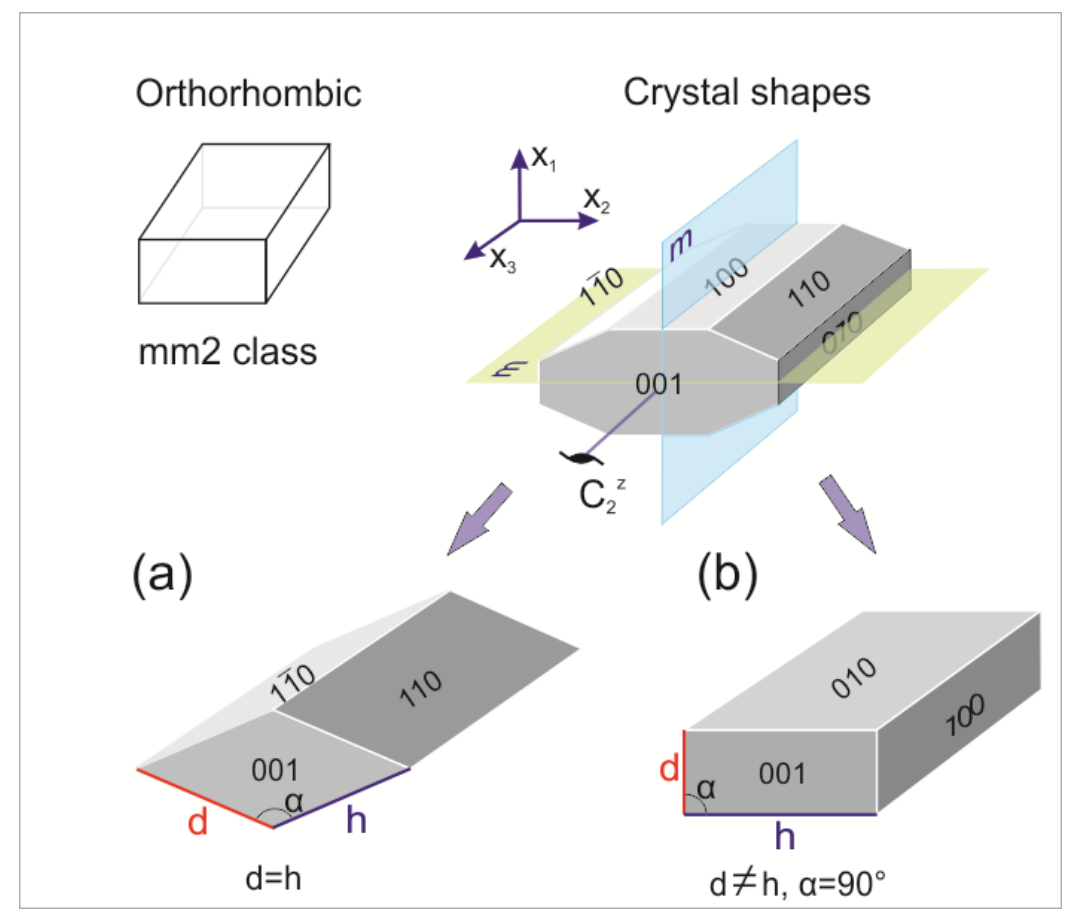

Figure S12. Schematic of crystal morphologies with noncentrosymmetric orthorhombic class $m m 2$. (a) Rhombic shape of asgrown crystal of 1. (b) Orthogonal shape.

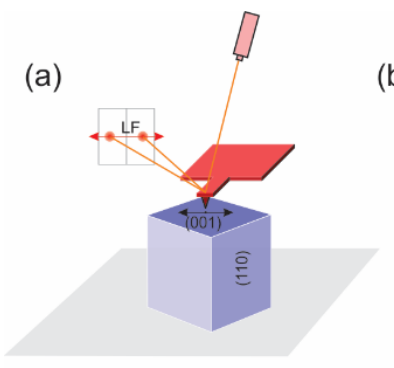

(b)

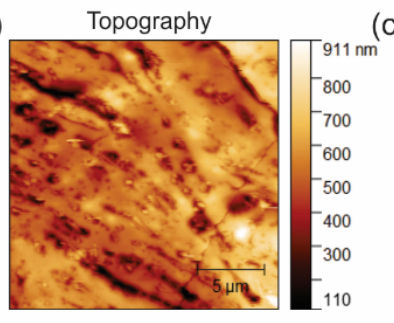

(e)

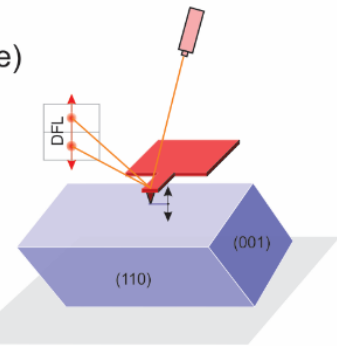

(f)

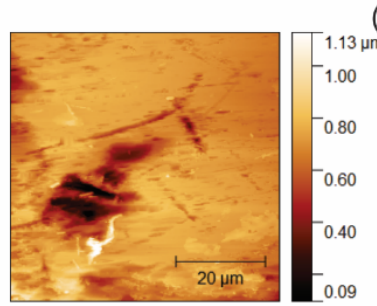

(c)

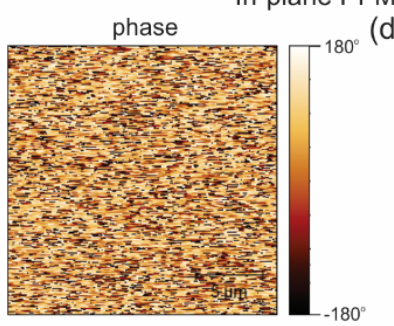

(d)

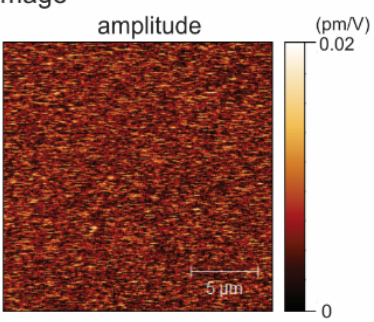

Out-of-plane PFM image

(g)

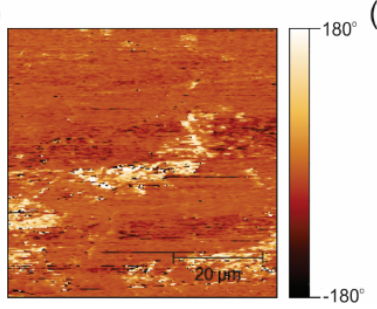

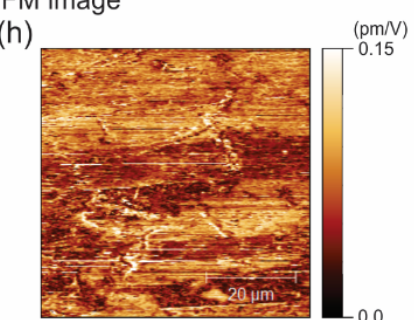

Figure S13. Ferroelectric domain structures obtained by PFM. Schematic of the in-plane, LF (lateral force) signal (a) and out-ofplane, DFL (deflection) signal (e) measurements. (Topography (b), phase (c) and amplitude (d) of lateral PFM map measured on the (001) surface of crystal 1. Topography (f), phase (g) and amplitude (h) of vertical PFM map measured on the (110) surface of crystal 1. 
(a)

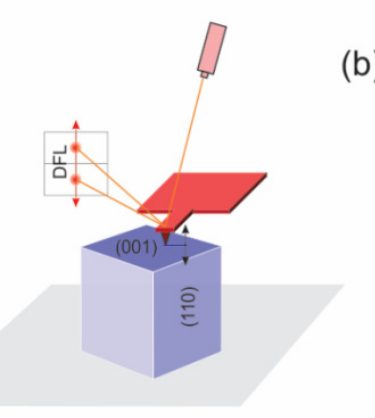

(b)
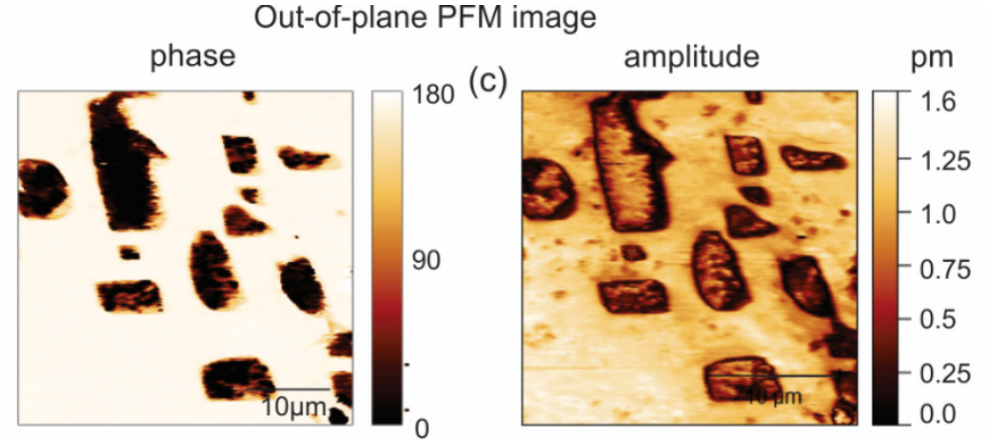

(d)

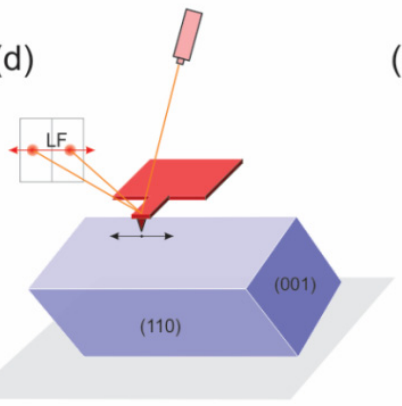

(e)

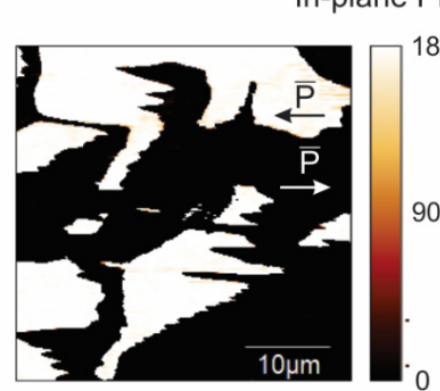

180 (f)

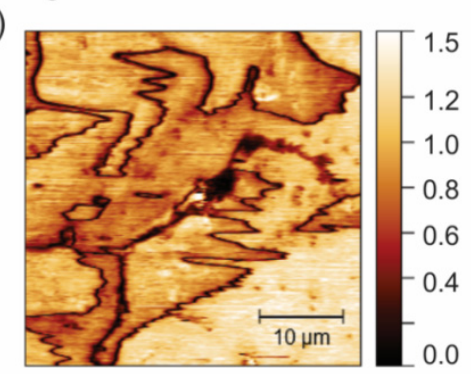

Figure S14. Ferroelectric domain structures obtained by PFM before annealing at room temperature. Schematic of the out-of-plane (a) and in-plane (d) measurements. Phase (b) and amplitude (c) of vertical PFM map measured on the (001) surface of crystal 1. Phase (e) and amplitude (f) of lateral PFM map measured on the (110) surface of crystal 1. 

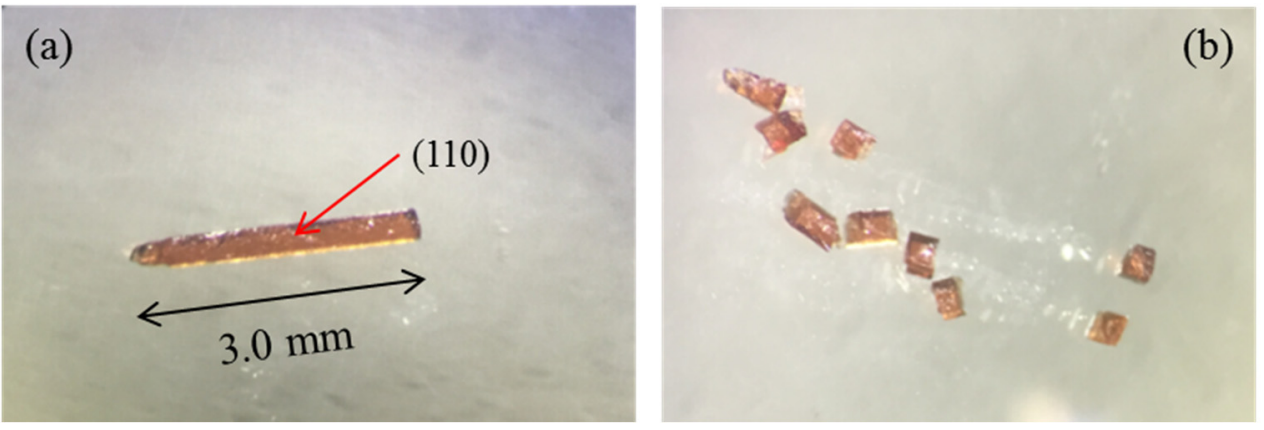

Figure S15. (a) Crystals of 1 obtained by the solvent evaporation method. (b) Cutting the crystal into several parts for PFM measurement.

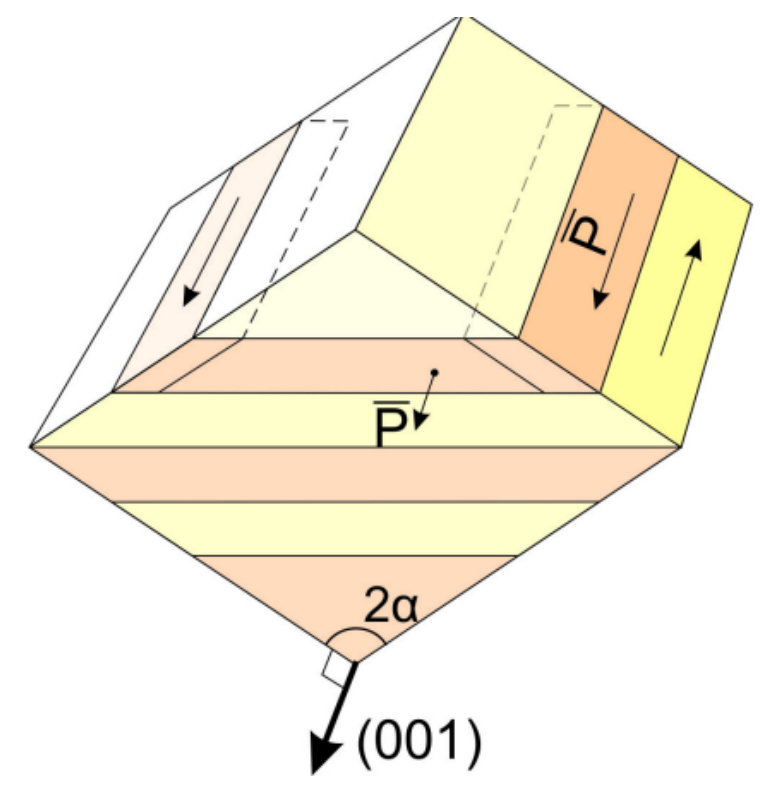

Figure S16. Schematic of the resulting domain structure for a single crystal of $\mathbf{1}$ after annealing.

(a)

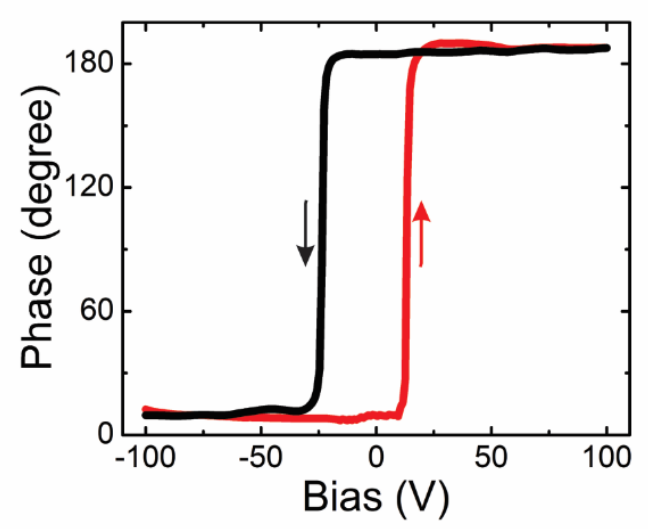

(b)

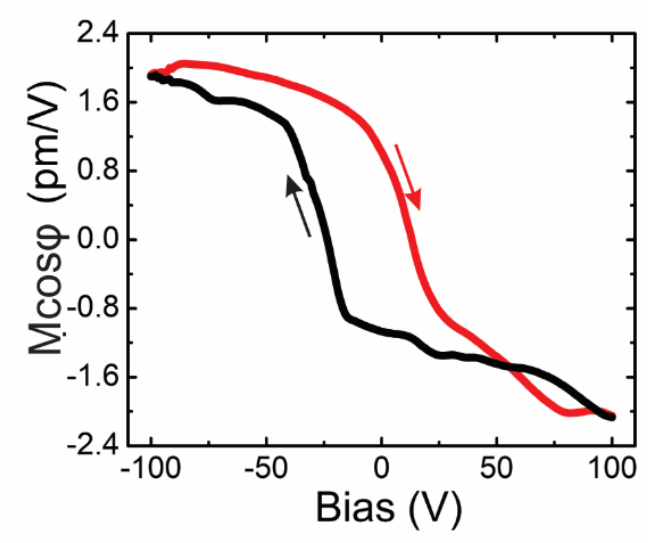

Figure S17. Local phase $\varphi(\mathrm{a})$ and magnitude $M \cos (\varphi)$ hysteresis loops (b). 


\section{PFM Measurements}

Imaging of the domain configurations and ferroelectric switching were carried out by piezoresponse force microscopy (PFM). The method is based on the detection of the mechanical response of a sample to an applied ac voltage due to the converse piezoelectric effect. In-contact topography as well as vertical and lateral piezoresponse images were obtained simultaneously. Out-of-plane PFM is measured through the cantilever response (DFL) along the normal to the sample surface, while for in-plane PFM imaging, the lateral response (LF) of the cantilever is utilized (Figure S7 (e), (a)).

Application of ac voltage $V_{\mathrm{ac}}=V_{0} \cos (\omega t)$ induces deformation of the sample surface detected by PFM as a signal M.cos $(\omega t+\varphi)$. The phase $\varphi$ and amplitude $M$ values were extracted by lock-in amplifier using $V_{\mathrm{ac}}=V_{0} \cos (\omega t)$ as reference signal. The phase $\varphi$ and magnitude $M \cdot \cos (\varphi)$ hysteresis loops for out-of-plain (DFL) signal are shown in Fig. S10.

Following the Neumann's principle, a noncentrosymmetric orthorhombic crystal of symmetry class $m m 2$ possesses five independent components of piezoelectric tensor $d_{i j}{ }^{[4]}$ :

$$
d=\left(\begin{array}{cccccc}
0 & 0 & 0 & 0 & d_{15} & 0 \\
0 & 0 & 0 & d_{24} & 0 & 0 \\
d_{31} & d_{32} & d_{33} & 0 & 0 & 0
\end{array}\right) .
$$

Here a short notation by the Voigt indices is used: $11 \rightarrow 1 ; 22 \rightarrow 2 ; 33 \rightarrow 3 ; 23 \rightarrow 4 ; 13 \rightarrow 5 ; 12 \rightarrow 6 .{ }^{[5]}$ When the electric field is applied, the elastic strain $u_{j k}$ is expressed as following: $u_{j k}=d_{i j k} E_{i}$.

Components of piezoelectric tensor responsible for main contribution into lateral and vertical PFM can be defined in the uniform field approximation model, according to this model the vertical response (Fig. S11) can be estimated as integral from the longitudinal elastic strain $u_{33}$ over the crystal height:

$$
u_{3} \approx \int_{0}^{h} d_{33} E\left(0,0, x_{3}\right) d x_{3}=d_{33} \cdot U_{\text {bias }}
$$

Where zero of coordinate system is chosen in contact point between probe and sample surface.

The lateral response can be estimated as integral from the shear elastic strain over the crystal thickness $t$ (Fig S12.). According to schematic image in Figure S12, the electric field components are: $E_{1}=E \cdot \cos (\alpha)$ and $E_{2}=E \cdot \sin (\alpha)$, then:

$$
u_{\text {lat }} \approx \int_{0}^{t}\left(d_{24} \sin (\alpha)+d_{15} \cos (\alpha)\right) E\left(x_{1}^{\prime}, 0,0\right) d x_{1}^{\prime}=\left(d_{24} \sin (\alpha)+d_{15} \cos (\alpha)\right) \cdot U_{\text {bias }}
$$

Zero of coordinate system is chosen in contact point between probe and sample surface.

Using relation $\operatorname{tg}(\alpha)=a / b$, where $a=14.3362(3) \AA$ and $b=11.7114(2) \AA$ are unit cell parameters, we obtain:

$$
u_{\text {lat }} \approx 0.77\left(d_{24}+0.82 \cdot d_{15}\right) \cdot U_{\text {bias }} \text {. }
$$

To estimate values of the piezoelectric coefficients, $0.77\left(d_{24}+0.82 \cdot d_{15}\right)$ and $d_{33}$, in our crystal we compared the vertical and lateral piezoresponse with test sample of Y-cut and X-cut quartz single crystals, correspondingly. Taking into account $d_{26}$ and $d_{11}$ piezoelectric coefficients for quartz $4.6 \mathrm{pm} / \mathrm{V}$ and $2.3 \mathrm{pm} / \mathrm{V},{ }^{[4]}$ correspondingly, we estimated effective piezocoefficients. The corresponding effective values for piezoelectric coefficients estimated from PFM data are listed in Table S1: 
Table S1. Piezoelectric coefficients estimated from PFM.

\begin{tabular}{|l|l|}
\hline piezoelectric oefficients, $d_{\mathrm{ij}}$ & $\mathrm{pm} / \mathrm{V}$ \\
\hline$d_{33}$ & $1.9-3.0$ \\
\hline$d_{24}+0.82^{*} d_{15}$ & $3.1-4.7$ \\
\hline
\end{tabular}




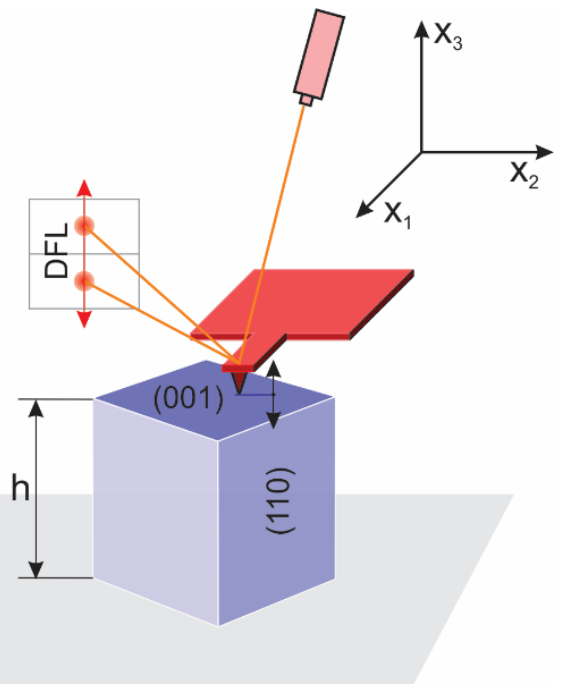

Figure S18. Schematics of the cantilever and principal axes orientation for out-of-plane measurements.

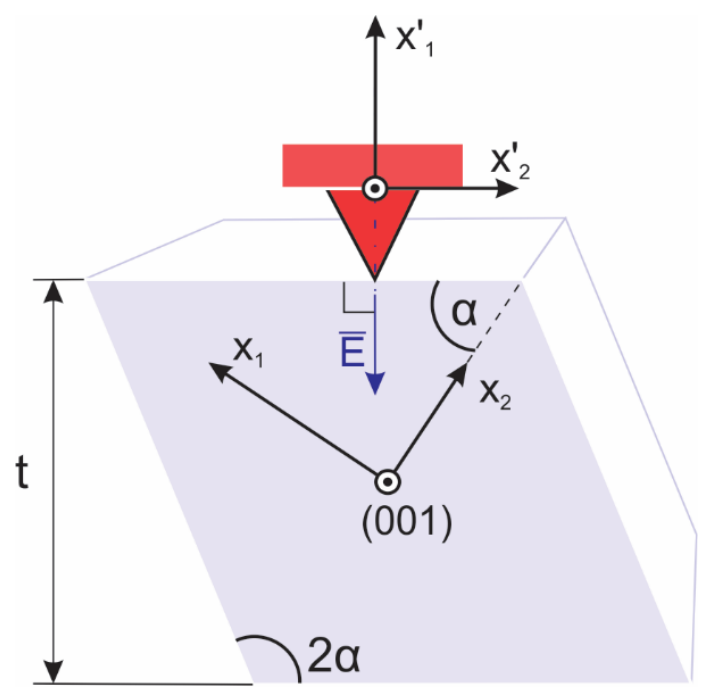

Figure S19. Cross-section of 1 crystal and schematics of the cantilever and principal axes orientation for in-plane measurements. $\operatorname{tg}(\alpha)=a / b$, where $a$ and $b$ are unit cell parameters. 


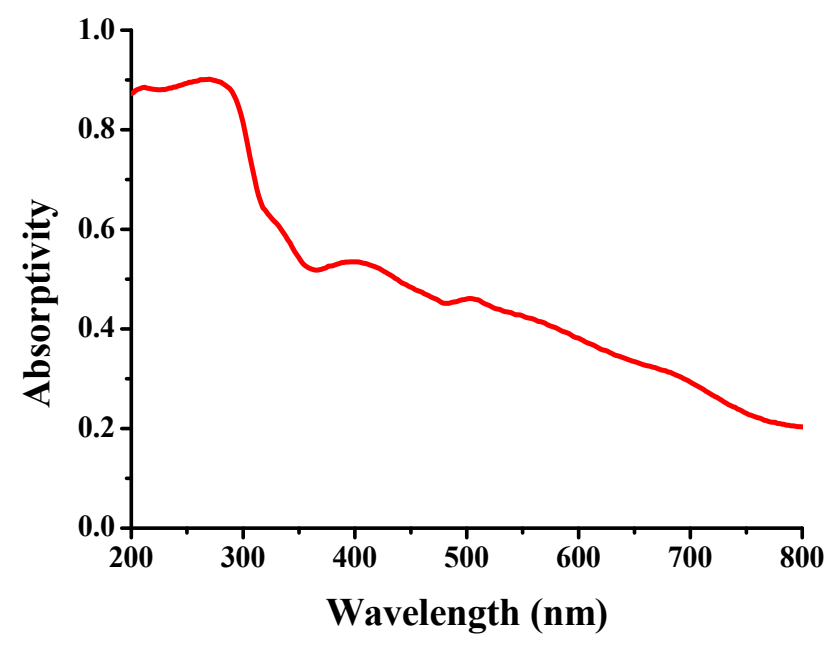

Figure S20. UV-Vis absorption spectrum of $\mathbf{1}$ at room temperature.

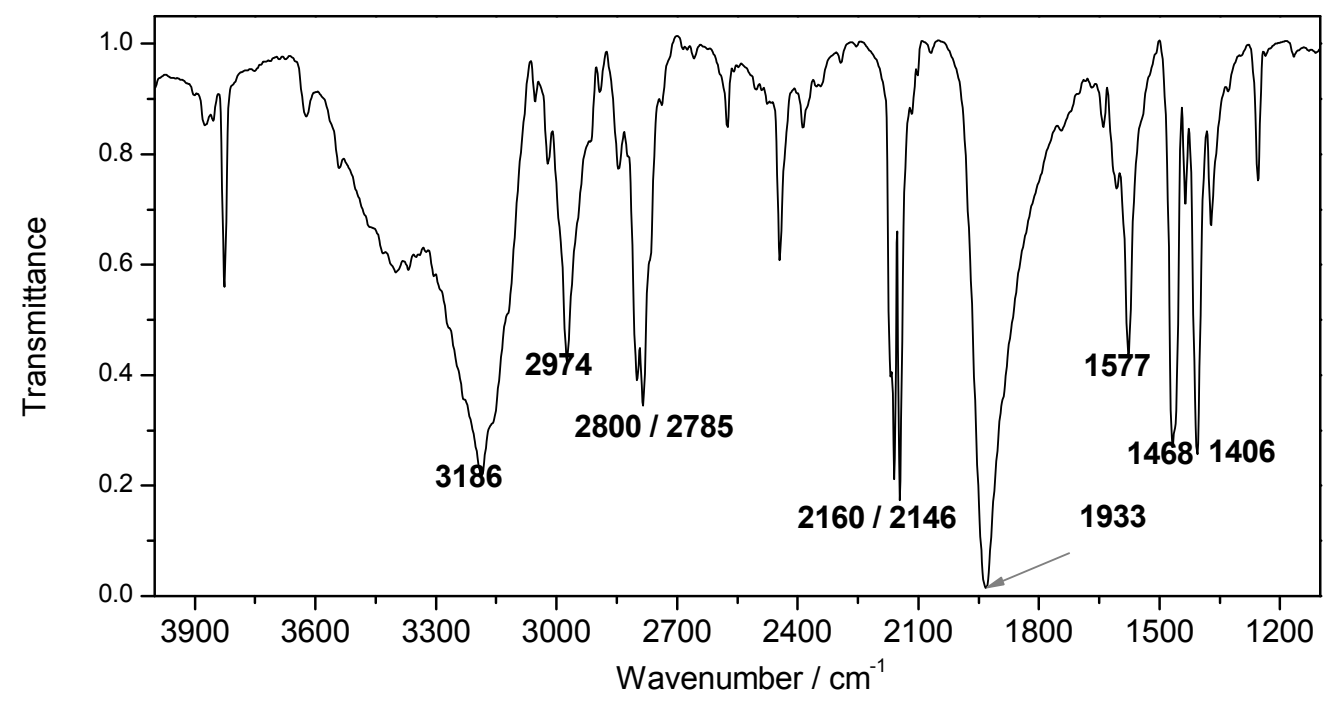

Figure S21. Infrared spectrum of $\mathbf{1}$ before irradiation. 
Table S2. Crystal data and structure refinement parameters for $\mathbf{1}$

\begin{tabular}{|c|c|c|}
\hline Phase & HTP & LTP \\
\hline Formula & \multicolumn{2}{|c|}{$\mathrm{C}_{7} \mathrm{H}_{8} \mathrm{FeN}_{7} \mathrm{NaO}$} \\
\hline Formula weight $(\mathrm{g} / \mathrm{mol})$ & \multicolumn{2}{|c|}{285.04} \\
\hline Temperature (K) & $453(2)$ & 293(2) \\
\hline Crystal system & Orthorhombic & Orthorhombic \\
\hline Space group & Pnam (No. 62) & $\operatorname{Pna2}_{1}$ (No. 33) \\
\hline$a / \AA$ & $13.7561(3)$ & $14.3362(3)$ \\
\hline$b / \AA$ & $12.4206(3)$ & $11.7114(2)$ \\
\hline$c / \AA$ & $7.7437(2)$ & $7.6484(1)$ \\
\hline$V / \AA^{3}$ & $1323.08(5)$ & $1284.14(4)$ \\
\hline$Z$ & 4 & 4 \\
\hline$D_{\mathrm{c}} / \mathrm{g} \mathrm{cm}^{-3}$ & 1.431 & 1.474 \\
\hline$R_{1}^{a}(>2 \sigma(I))$ & 0.0413 & 0.0383 \\
\hline$w R_{2}^{b}$ (all data) & 0.1122 & 0.1143 \\
\hline GOF & 1.062 & 1.152 \\
\hline Flack & / & $-0.003(6)$ \\
\hline BASF & / & 0.50357 \\
\hline CCDC number & 1978416 & 1978415 \\
\hline
\end{tabular}

${ }^{a} R_{1}=\sum \| F_{\mathrm{o}} \mid-=\left\{\sum w\left[\left(F_{\mathrm{o}}\right)^{2}-\left(F_{\mathrm{c}}\right)^{2}\right]^{2} / \sum w\left[\left(F_{\mathrm{o}}\right)^{2}\right]^{2}\right\}^{1 / 2}$ 
Table S3. Hydrogen bonds in the HTP and LTP of 1

\begin{tabular}{|c|c|c|c|c|c|}
\hline Phase & $\mathrm{D}$ & $\mathrm{H}$ & $\mathrm{A}$ & $d(\mathrm{D}-\mathrm{A}) / \AA$ & D-H-A/ ${ }^{\circ}$ \\
\hline \multirow{4}{*}{ HTP } & N5 & H5A & N3 & $3.210(8)$ & 123.1 \\
\hline & N5 & H5A & $\mathrm{N} 2$ & $3.405(8)$ & 148.3 \\
\hline & N5 & H5B & $\mathrm{N} 3^{1}$ & $3.400(12)$ & 160.4 \\
\hline & \multicolumn{5}{|c|}{ Symmetry codes: ${ }^{1}(+x,+y, 1 / 2-z)$} \\
\hline \multirow{4}{*}{ LTP } & N7 & $\mathrm{H} 7 \mathrm{~A}$ & $\mathrm{~N} 2^{1}$ & $3.095(7)$ & 139.9 \\
\hline & N7 & $\mathrm{H} 7 \mathrm{~A}$ & $\mathrm{~N} 1^{2}$ & $3.383(8)$ & 131.3 \\
\hline & N7 & H7B & $\mathrm{N} 5^{3}$ & $3.090(7)$ & 153.6 \\
\hline & \multicolumn{5}{|c|}{ Symmetry codes: ${ }^{1}(1 / 2-x, 1 / 2+y, 1 / 2+z) ;{ }^{2}(-1 / 2+x, 1 / 2-y, 1+z) ;{ }^{3}(1-x, 1-y, 1 / 2+z)$} \\
\hline
\end{tabular}


Table S4. Selected bond distances (A) for 1

\begin{tabular}{|c|c|c|c|c|c|c|c|}
\hline Phase & Atom & Atom & Length/Å & Phase & Atom & Atom & Length/Å \\
\hline \multirow{20}{*}{ LTP } & $\mathrm{Fe} 1$ & N6 & $1.650(3)$ & \multirow{20}{*}{ HTP } & $\mathrm{Fe} 1$ & N4 & $1.635(3)$ \\
\hline & $\mathrm{Fe} 1$ & $\mathrm{C} 1$ & $1.947(4)$ & & $\mathrm{Fe} 1$ & $\mathrm{C} 1$ & $1.937(3)$ \\
\hline & $\mathrm{Fe} 1$ & $\mathrm{C} 2$ & $1.935(5)$ & & $\mathrm{Fe} 1$ & $\mathrm{C} 2$ & $1.933(3)$ \\
\hline & $\mathrm{Fe} 1$ & C3 & $1.932(5)$ & & $\mathrm{Fe} 1$ & C3 & $1.935(2)$ \\
\hline & $\mathrm{Fe} 1$ & $\mathrm{C} 4$ & $1.936(5)$ & & $\mathrm{Fe} 1$ & $\mathrm{C} 2^{1}$ & $1.933(3)$ \\
\hline & $\mathrm{Fe} 1$ & $\mathrm{C} 5$ & $1.940(5)$ & & $\mathrm{Fe} 1$ & $C 3^{1}$ & $1.935(2)$ \\
\hline & $\mathrm{Na} 1$ & $\mathrm{~N} 2^{1}$ & $2.476(6)$ & & $\mathrm{Na} 1$ & N3 & $2.452(2)$ \\
\hline & $\mathrm{Na} 1$ & $\mathrm{~N} 4^{2}$ & $2.406(5)$ & & $\mathrm{Na} 1$ & $\mathrm{~N} 3^{2}$ & $2.452(2)$ \\
\hline & $\mathrm{Na} 1$ & N3 & $2.425(5)$ & & $\mathrm{Na} 1$ & N1 & $2.410(3)$ \\
\hline & $\mathrm{Na} 1$ & $\mathrm{~N} 1^{3}$ & $2.410(4)$ & & $\mathrm{Na} 1$ & $\mathrm{~N} 2$ & $2.431(2)$ \\
\hline & $\mathrm{Na} 1$ & $\mathrm{~N} 5^{4}$ & $2.476(4)$ & & $\mathrm{Na} 1$ & $\mathrm{~N} 2^{2}$ & $2.431(2)$ \\
\hline & N6 & $\mathrm{O} 1$ & $1.136(6)$ & & $\mathrm{C} 2$ & $\mathrm{~N} 2^{3}$ & $1.132(4)$ \\
\hline & $\mathrm{C} 4$ & N4 & $1.157(7)$ & & $\mathrm{C} 3$ & N3 & $1.129(3)$ \\
\hline & $\mathrm{C} 2$ & $\mathrm{~N} 2$ & $1.151(8)$ & & N4 & O1 & $1.126(5)$ \\
\hline & N7 & $\mathrm{C} 7$ & $1.465(7)$ & & $\mathrm{C} 1$ & $\mathrm{~N} 1^{4}$ & $1.124(4)$ \\
\hline & N7 & C6 & $1.465(6)$ & & N1 & $\mathrm{C} 1^{5}$ & $1.124(4)$ \\
\hline & $\mathrm{C} 1$ & N1 & $1.131(6)$ & & $\mathrm{N} 2$ & $\mathrm{C} 2^{6}$ & $1.132(4)$ \\
\hline & C3 & N3 & $1.152(7)$ & & N5 & $\mathrm{C} 4$ & $1.398(9)$ \\
\hline & $\mathrm{C} 5$ & N5 & $1.144(7)$ & & N5 & $\mathrm{C} 5$ & $1.446(8)$ \\
\hline & \multicolumn{3}{|c|}{$\begin{array}{l}\text { Symmetry codes: } \\
{ }^{1}(1 / 2+x, 1 / 2-y,+z) ;{ }^{2}(1 / 2+x, 1 / 2-y, 1+z) ; \\
{ }^{3}(3 / 2-x, 1 / 2+y, 1 / 2+z) ;{ }^{4}(+x,+y, 1+z)\end{array}$} & & \multicolumn{3}{|c|}{$\begin{array}{l}\text { Symmetry codes: }{ }^{1}(+x,+y, 1 / 2-z) ; \\
{ }^{2}(+x,+y, 3 / 2-z) ;{ }^{3}(-1 / 2+x, 1 / 2-y,+z) ;{ }^{4}(3 / 2- \\
x,-1 / 2+y,-1 / 2+z) ;{ }^{5}(3 / 2-x, 1 / 2+y, 1 / 2+z) ; \\
{ }^{6}(1 / 2+x, 1 / 2-y,+z)\end{array}$} \\
\hline
\end{tabular}


Table S5. Wavenumbers of nitrosyl bands in some metal nitrosyl derivatives based on $\left[\mathrm{M}(\mathrm{CN})_{5} \mathrm{NO}\right]^{2-}$

\section{References}

\begin{tabular}{|c|c|c|c|c|c|c|}
\hline Compound & $v_{\mathrm{GS}}(\mathrm{NO})$ & $v_{\mathrm{SI}}(\mathrm{NO})$ & $v_{\mathrm{SII}}(\mathrm{NO})$ & $\begin{array}{l}\text { Shift } \\
\text { (GS-SI) }\end{array}$ & $\begin{array}{l}\text { Shift (GS- } \\
\text { SII) }\end{array}$ & Reference \\
\hline $\begin{array}{l}\left(\mathrm{Me}_{2} \mathrm{NH}_{2}\right)\left[\mathrm{NaFe}(\mathrm{CN})_{5}(\mathrm{NO})\right] \\
(\mathbf{1})\end{array}$ & 1933 & $\begin{array}{l}1827 \\
1795\end{array}$ & $\begin{array}{l}1664, \\
1633\end{array}$ & 106 & 269 & This work \\
\hline $\mathrm{Na}_{2}\left[\mathrm{Fe}(\mathrm{CN})_{5}(\mathrm{NO})\right] \cdot 2 \mathrm{H}_{2} \mathrm{O}$ & 1947 & 1835 & 1664 & 112 & 283 & $\begin{array}{l}\text { Inorg. Chem., 1970, } \\
9,13 .\end{array}$ \\
\hline $\mathrm{Na}_{2}\left[\mathrm{Ru}(\mathrm{CN})_{5}(\mathrm{NO})\right] \cdot 2 \mathrm{H}_{2} \mathrm{O}$ & 1932 & $\begin{array}{l}1847, \\
1839, \\
1835\end{array}$ & 1648 & 85 & 284 & $\begin{array}{l}\text { Solid State } \\
\text { Commun., 1997, } \\
\text { 101, } 471 .\end{array}$ \\
\hline $\mathrm{Na}_{2}\left[\mathrm{Os}(\mathrm{CN})_{5}(\mathrm{NO})\right] \cdot 2 \mathrm{H}_{2} \mathrm{O}$ & 1897 & $\begin{array}{l}1799, \\
1790, \\
1788 \\
\text { (shoulder) }\end{array}$ & 1546 & 98 & 351 & $\begin{array}{l}\text { Solid State } \\
\text { Commun., 1997, } \\
\text { 101, } 471 .\end{array}$ \\
\hline $\mathrm{K}_{3}\left[\mathrm{Mn}(\mathrm{CN})_{5}(\mathrm{NO})\right] \cdot 2 \mathrm{H}_{2} \mathrm{O}$ & $\begin{array}{l}1733 \\
1743\end{array}$ & / & 1399 & / & 344 & $\begin{array}{l}\text { Phys. Chem. Chem. } \\
\text { Phys., 2009, 11, } \\
4391 .\end{array}$ \\
\hline
\end{tabular}

[1] R. Jacobson, REQAB. Molecular Structure Corporation. The Woodlands, Texas, USA1998.

[2] G. M. Sheldrick, XL. Acta Cryst. 2008, A64, 112.

[3] O.V. Dolomanov, L.J. Bourhis, R.J. Gildea, J.A.K. Howard, H. Puschmann, J. Appl. Cryst. 2009, 42, 339.

[4] Accelrys, Materials Studio Getting Started, release 5.0; Accelrys Software, Inc: San Diego, CA, 2009

[5] J. F. Nye, Physical Properties of Crystals: Their Representation by Tensors and Matrices, Oxford University Press, 1985. 